\title{
Migration of Implanon ${ }^{\circledR}$
}

\author{
Hanan Ismail, Diana Mansour, Madan Singh
}

\section{Abstract}

Objective To determine whether or not migration of the Implanon ${ }^{\circledR}$ rod does occur if correctly positioned and, if indeed migration does occur, to measure the degree of such migration.

Methods A prospective study of 100 women who requested and had Implanon rods inserted by one fully trained health care professional holding the Faculty of Family Planning and Reproductive Health Care Letter of Competence in Subdermal Contraceptive Implant Techniques. Measurements were made from the insertion site to the distal end of the rods at 3 and 12 months post-insertion.

Results Of the 100 women studied, 95 were seen for followup at 3 months. There was no migration of Implanon in 58 $(61 \%)$ patients. Of the remaining $37(39 \%)$ patients where migration had occurred, 34 showed migration caudally and only three demonstrated cranial migration. With regard to the degree of migration, all but one case showed this to be less than $2 \mathrm{~cm}$ either cranially or caudally. At 1-year followup 87 patients were seen. No migration was noted in 39 $(45 \%)$ patients. In the remaining $48(55 \%)$ patients where migration had occurred, 44 showed migration caudally and only four demonstrated cranial migration, which in one case was over $2 \mathrm{~cm}$. With regard to the degree of migration, all but one case showed this to be less than $2 \mathrm{~cm}$ either cranially or caudally. The measurement in the single case showing migration over $2 \mathrm{~cm}$ at 3 months remained the same at the 1-year follow-up.

Conclusions These results show that up to 1 year after insertion of Implanon significant migration of the rod does not occur. The degree of migration noted in all cases except one was less than $2 \mathrm{~cm}$. Where migration was noted, in the majority of cases this occurred caudally towards the insertion site. There were no cases of deep migration.

J Fam Plann Reprod Health Care 2006; 32(3): 157-159 (Accepted 27 March 2006)

\section{Key message points}

- Significant migration of the Implanon ${ }^{\circledR}$ rod does not occur if correctly inserted.

- If migration does occur, in the majority of cases this was found to be in a caudal direction towards the insertion site.

- In all but one case where migration was noted this was less than $2 \mathrm{~cm}$.

Central Family Planning Clinic, Norfolk and Norwich University Hospital, Norwich, UK

Hanan Ismail, MB ChB, MFFP, Staff Grade in Family Planning and Reproductive Health Care

Newcastle-upon-Tyne Contraception and Sexual Health Services, Graingerville Clinic, Newcastle General Hospital, Newcastle-upon-Tyne, UK

Diana Mansour, FRCOG, FFFP, Consultant in Community Gynaecology and Reproductive Health Care

Department of Obstetrics and Gynaecology, Royal Victoria Infirmary, Newcastle-upon-Tyne, UK

Madan Singh, DM, FRCOG, Emeritus Consultant in Obstetrics and Gynaecology and former Senior Lecturer in Family Planning

Correspondence to: Dr Hanan Ismail, Central Family Planning Clinic, Grove Road, Norwich NRI 3RH, UK.

E-mail: HANAN.ISMAIL@nnuh.nhs.uk

\section{Introduction}

Although migration of subdermal contraceptive implants has been reported previously in relation to Norplant ${ }^{\circledR}$, the six-rod contraceptive system, a MEDLINE search up to 2004 regarding migration of Implanon ${ }^{\circledR}$ found no reports. More recently, however, there has been a report suggesting similar movement of Implanon but in patients who had the rod inserted immediately after removal of Norplant and at the same site. Buckshee et al. ${ }^{1}$ reported a $5.8 \%$ incidence of migration in a study of 1466 women using Norplant II ${ }^{\circledR}$ over a 5-year period. In that study the implants had migrated to the elbow crease in two subjects. Oloto and Bromham ${ }^{2}$ stated that migration of more than $2 \mathrm{~cm}$ for Norplant capsules had never been reported. Cozens ${ }^{3}$ then published a case in which migration of Norplant capsules had occurred. Two capsules were found to be in a satisfactory position but the third, fourth and fifth capsules had migrated cranially by roughly 15, 40 and $40 \mathrm{~mm}$, respectively, and the sixth capsule had migrated over $50 \mathrm{~mm}$ caudally. With regard to movement of Implanon, Evans et al. ${ }^{4}$ reported two cases in which the distal ends of Implanon rods were found to be 11 and $7.3 \mathrm{~cm}$ from the insertion site. In both cases the Implanon rod had been inserted immediately following removal of Norplant using the same removal incision for entry. The assumption was made that this was a contributory factor in the migration of the implants. The present study was a prospective review of patients who had Implanon inserted to determine the degree of migration that might be encountered in the general population of Implanon users. In none of these cases was Implanon inserted following removal of Norplant.

\section{Implanon and its method of insertion}

Implanon is a long-acting contraceptive method that to date has been used in 36 countries. It is a single-rod, progestogen-only implant measuring $4 \mathrm{~cm}$ in length and 2 $\mathrm{mm}$ in diameter. It is not biodegradable and contains $68 \mathrm{mg}$ etonogestrel within a flexible ethylene vinylacetate copolymer. It was launched in the UK in September 1999, following one of the most extensive trial programmes ever performed for a contraceptive product. During more than 70000 cycles of treatment in over 2300 women no pregnancies occurred. The Pearl index derived from these studies has been reported to be zero; however, the confidence interval of 0.00 to 0.07 indicates that in clinical practice failures may occur. 5

Instructions for insertion state that Implanon should be placed subdermally at the inner side of the upper nondominant arm about $7 \mathrm{~cm}$ above the elbow crease in the groove between the biceps and the triceps. The procedure is carried out using an aseptic technique under local anaesthesia. The needle of the Implanon inserter is introduced in the above-mentioned space, directly under the skin. By tenting the skin with the tip of the needle, the needle should be inserted in a cranial direction to its full length. 6 The obturator is rotated $90^{\circ}$ before being firmly secured in place, and the needle is slowly withdrawn, releasing the implant into the correct plane and position in the arm. The inserter needle is $1 \mathrm{~cm}$ longer than the obturator so that following insertion the distance between the implant and the entry wound should be $1 \mathrm{~cm}$. 


\section{ARTICLE}

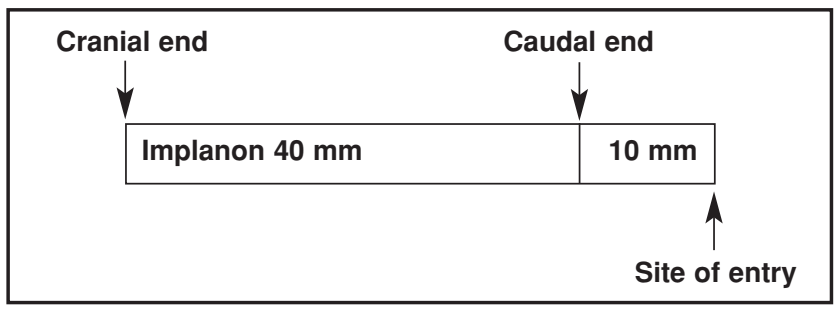

Figure 1 Method of measuring implant migration

\section{Methods}

This was a prospective survey of 100 consecutively attending women, aged between 16 and 39 years, requesting Implanon in a city contraception and sexual health service. A family planning doctor who had undertaken the approved training course and who holds the Faculty of Family Planning and Reproductive Health Care Letter of Competence in Subdermal Contraceptive Implant Techniques inserted all the implants. Following Implanon insertion, the distance between the skin wound and the caudal end of the implant was measured. In an ideal situation this should measure $1 \mathrm{~cm}$ as illustrated in Figure 1. The migration, either cranially or caudally, was then measured in millimetres in relation to this standard at subsequent clinic visits.

\section{Results}

In all 100 women the distance from the skin wound to the caudal end of the implant was recorded immediately and all measured $1 \mathrm{~cm}$. The implants were all palpable subdermally following insertion and on subsequent clinic visits. After Implanon insertion each woman was requested to return for follow-up examination at 3 and 12 months unless they experienced problems in the interim period. Five women failed to return to the clinic following insertion. A total of six women had their Implanon removed in the interval after 3 months but before 1 year, citing bleeding problems as their reason for discontinuation. In the same time interval, a further two Implanon rods were removed as the two women concerned wanted to conceive. In these eight cases no movement of Implanon was found at the time of removal. Between the 3- and 12-month appointment times little movement of the implant was demonstrated.

Figure 2 illustrates the degree of migration of Implanon in the 95 patients seen for follow-up at 3 months. In 58 $(61 \%)$ patients no migration was noted. In the remaining 37 (39\%) patients where migration had occurred, 34 showed migration caudally and only three demonstrated cranial migration, which in one case was over $2 \mathrm{~cm}$.

Figure 3 illustrates the degree of migration in the 87 patients seen for follow-up at 12 months. In 39 (45\%) patients there was no migration. In the remaining 48 (55\%) patients where migration had occurred, 44 showed

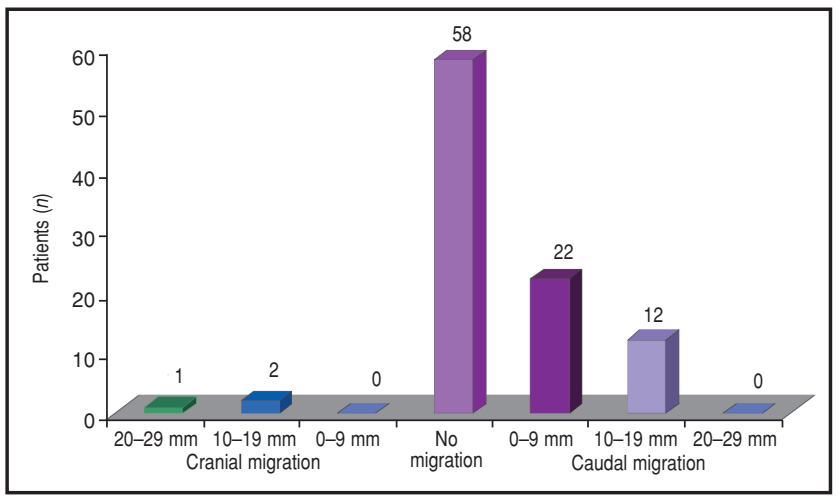

Figure 2 Migration of Implanon ${ }^{\circledR} 3$ months after insertion

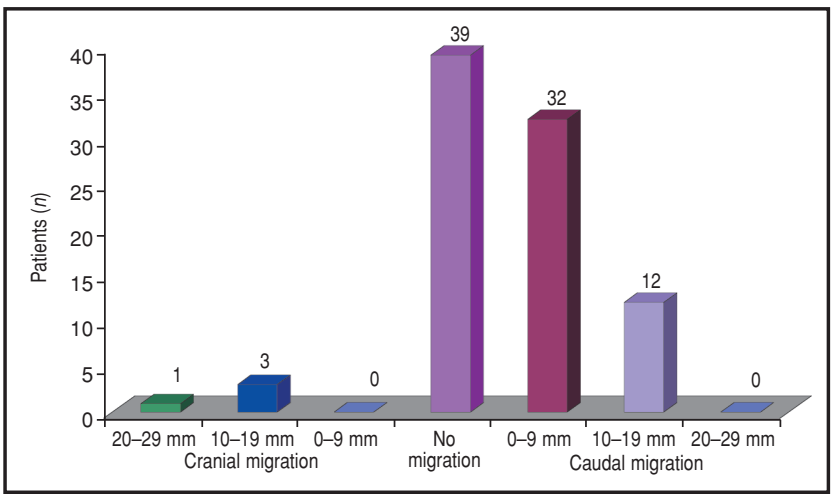

Figure 3 Migration of Implanon ${ }^{\circledR} 12$ months after insertion

migration caudally and only four demonstrated cranial migration, which in one case was over $2 \mathrm{~cm}$. The single case showing migration over $2 \mathrm{~cm}$ at 1 year was the same case that showed migration over $2 \mathrm{~cm}$ at 3 months.

\section{Discussion}

This survey was undertaken to determine the degree of migration, if any, of Implanon implants subsequent to their insertion. Taking as a measurable standard the distance between the caudal end of the implant and the entry wound, the results show that there was migration of the rod caudally in some cases and cranially in others. Although no migration was demonstrated in $45 \%$ of cases, some degree of migration was noted in $55 \%$ of cases. In $44 / 87$ cases migration had occurred caudally, with just four cases occurring cranially. In relation to when migration occurs, the results of the present study demonstrate that most movement occurs within the first 3 months post-insertion. However, further movement can occur in about $11 \%$ of cases up to 12 months following commencement of this method.

With regard to the degree of migration, in the majority of cases where migration does occur this is 19 $\mathrm{mm}$ or less. In only one patient was movement of more than $19 \mathrm{~mm}$ recorded. Although the present study investigating Implanon migration is, on the whole, in agreement with the previous Norplant study reported by Oloto and Bromham, ${ }^{2}$ we have identified one case where movement had occurred beyond $2 \mathrm{~cm}$. Poor insertion technique may account for those cases where implant migration over $2 \mathrm{~cm}$ is documented. It is vital that the obturator is fixed by the health professional before removal of the needle, as pushing the obturator against the implant on insertion will lead to cranial displacement. Failure to fix the obturator adequately at insertion will result in the implant being placed too near the insertion site, resulting in caudal displacement and even possible expulsion of the implant within the first few days following insertion.

It is stated that correct placement of the implant in the sulcus (the groove between the biceps and the triceps) limits implant migration; 6 however, it is our practice to insert Implanon over the anterior body of the biceps muscle. This has not resulted in excess movement and reduces the risk of damage to the neurovascular bundle at removal if deep insertion is inadvertently performed by a trainee or poorly trained provider.

Of all the cases studied it should be noted that none demonstrated migration deep into subcutaneous tissues or muscle. Theoretically, if the implant is inserted into the biceps muscle, significant migration may result. We therefore conclude that movement over $2 \mathrm{~cm}$ should not occur if the correct subdermal insertion procedure is followed and carried out by a properly trained individual. 
Statements on funding and competing interests

Funding. None identified.

Competing interests. Diana Mansour has received lecture fees, financial support for attending conferences and consultancy fees from a number of pharmaceutical companies.

References

1 Buckshee K, Chatterjee P, Dhall GI, Hazra MN, Kodkhany BS, Lalitha K. Phase III clinical trial with Norplant II (two covered rods): report on five years of use. Contraception 1993; 48: 120-132.
2 Oloto EJ, Bromham DR. Norplant removal: a review. Br J Fam Plann 1995; 21(Suppl.): 21-24.

3 Cozens NJ. Contraceptive implants: high-resolution ultrasonography facilitates removal (Letter). BMJ 1996; 313: 880.

4 Evans R, Holman R, Lindsay E. Migration of Implanon ${ }^{\circledR}$ : two case reports. J Fam Plann Reprod Health Care 2005; 31: 71-72.

5 Croxatto HB, Makarainen L. The pharmacodynamics and efficacy of Implanon. Contraception 1998; 58: 91S-97S

6 Organon Laboratories Ltd. Implanon: Summary of Product Characteristics. December 2003. http://www.medicines.org.uk

\section{MEMBERSHIP OF THE FACULTY OF FAMILY PLANNING AND REPRODUCTIVE HEALTH CARE}

The Membership Examination (MFFP) consists of:

\section{Part 1 Multiple Choice Question paper (MCQ)}

This 11/2-hour paper consists of 50 clinical science and applied science questions.

The examination will be held in London on Tuesday 24 April 2007 (applications must be received by 1 January 2007) and Friday 19 October 2007 (applications must be received by 1 July 2007). The application form and information on the Part 1 can be obtained from the Faculty of Family Planning website (www.ffprhc.org.uk).

\section{Dissertation or Case Reports}

Submission of one Dissertation (10 000 words) or two Case Reports (3000 words each).

Please visit the Faculty of Family Planning website (www.ffprhc.org.uk) for the latest changes to this part of the examination, and for information on exemptions.

\section{$\square$ Part 2 Examination (CRQ, MEQ, OSCE)}

This all day examination consists of:

Critical Reading Question examination paper (CRQ)

Modified Essay Question examination paper (MEQ)

Objective Structured Clinical Examination (OSCE)

Applications for the MFFP Part 2 held in June 2007 must be received by Wednesday 3 January 2007. Please consult the revised Examination Regulations for changes to the entry requirements. Information on the Part 2 examination and the application form appear on the Faculty of Family Planning website (www.ffprhc.org.uk).

The qualification is subject to re-certification every 5 years.

For the revised MFFP Examination Regulations (December 2005), information and application forms please visit the Faculty of Family Planning website: www.ffprhc.org.uk (see Training \& Exams and MFFP Member). Also available on request from: Mrs Denise Pickford, Examinations, Faculty of Family Planning and Reproductive Health Care of the Royal College of Obstetricians and Gynaecologists, 27 Sussex Place, Regent's Park, London NW1 4RG, UK. Tel: +44 (0) 2077245629. Fax: +44 (0) 207723 5333. E-mail: denise@ffprhc.org.uk 